\title{
Principles for the formation of an effective concept of multifunctional high-rise construction investment projects
}

\author{
Sergei Beliakov ${ }^{1, *}$ \\ ${ }^{1}$ Moscow State University of Civil Engineering, Yaroslavskoe shosse, 26, Moscow, 129337, Russia
}

\begin{abstract}
Investment projects of high-rise construction have a number of features that determine specific risks and additional opportunities that require analysis and accounting in the formation of an effective project concept. The most significant features of high-rise construction include long construction time, complexity of technical and technological solutions, complexity of decisions on the organization of construction and operation, high cost of construction and operation, complexity in determining the ratio of areas designed to accommodate different functional areas, when organizing and coordinating the operation of the facility, with internal zoning. Taking into account the specificity of high-rise construction, among the factors determining the effectiveness of projects, it is advisable to consider as key factors: organizational, technological and investment factors. Within the framework of the article, the author singled out key particular functions for each group of factors under consideration, and also developed a system of principles for the formation of an effective concept of multifunctional high-rise construction investment projects, including the principle of logistic efficiency, the principle of optimal functional zoning, the principle of efficiency of equipment use, the principle of optimizing technological processes, the principle maximization of income, the principle of fund management, the principle of risk management. The model of formation of an effective concept of investment projects of multifunctional high-rise construction developed by the author can contribute to the development of methodological tools in the field of managing the implementation of high-rise construction projects, taking into account their specificity in the current economic conditions.
\end{abstract}

\section{Introduction}

In the conditions of high cost and shortage of land intended for construction in the large cities of Russia in recent decades, dynamic development has received high-rise construction, which allows to maximize the technical and economic parameters of investment projects in relation to the small size of the built-up area [1].

Typically, for the classification of high-rise buildings, the height criterion is used in meters, rather than in floors, because the heights of the floors are adopted different depending

${ }^{*}$ Corresponding author: serj-bel@yandex.ru 
on the purpose of the building and the requirements of national design standards. In Russia high-rise buildings are considered buildings with a height of more than 75 meters.

High-rise buildings can have different purposes: hotels, offices, residential buildings, however, given the large scale, most often high-rise buildings are designed as multifunctional, and in addition to premises for main purposes, parking lots, service facilities, etc. are located.

\section{Materials and Methods}

Investment projects of high-rise construction have a number of features that determine specific risks and additional opportunities that require analysis and accounting in the formation of an effective project concept. The most significant features of high-rise construction include:

\section{- long terms of construction,}

Investing in high-rise construction projects is of a long-term nature, since the construction time of high-rise buildings is substantially higher than for similar projects of low and medium-story level. At the same time, the effectiveness of projects of high-rise construction is significantly influenced by changes occurring in the economic environment. Therefore, the use of effective methods of forecasting, investment management and risk control becomes the most important factors determining the effectiveness of high-rise investment projects.

- complexity of technical and technological solutions,

The construction of high-rise buildings is associated with the need to develop unique technical and technological solutions, including those aimed at ensuring the acceptable level of safety at various stages of construction, as well as during operation and repair works [2].

- complexity of decisions on the organization of construction and operation,

The organization of construction of high-rise facilities, as a rule, requires the development of complex plans that ensure the rational performance of material support processes, the performance of construction work in the conditions of a limited construction site, environmental protection, security in construction, etc. Also, the solution of the problem of efficient operation of high-altitude objects, in particular, combining several functions is required.

- high cost of construction and operation,

The cost of construction and operating high-rise buildings is significantly higher than that of mass construction, and is due not only to specific design solutions, but also life support systems and complex security requirements.

- complexity in determining the ratio of areas designed to accommodate different functional areas, when organizing and coordinating the operation of the facility, with internal zoning.

The formation of the functional concept of a high-rise building is always connected with the need for a comprehensive analysis of target risk segments, long-term forecasting of the economic environment, complex analysis of the competitive environment, solving architectural and commercial tasks of the internal zoning of the facility, etc.

Thus, taking into account the specificity of high-rise construction, the issues of conceptual planning of the project are of particular importance, since at this stage prerequisites are formed for all further stages of project implementation and its risks and effectiveness are predetermined.

Depending on the nature of the factors that affect the efficiency of investment construction projects, it is customary to distinguish [3-6]:

- economic factors,

- social factors,

- administration factors, 
- environmental factors,

- organizational factors,

- technological factors,

- investment factors.

In accordance with this classification of factors, the objective function of the efficiency of the multifunctional high-rise construction investment project may be presented in the following form:

$$
E_{\text {project }}=f\left(\sum_{i=0}^{n}\left(\begin{array}{c}
F_{\text {economic }}^{i} ; F_{\text {social }}^{i} ; F_{\text {administration }}^{i} ; F_{\text {environmental }}^{i} ; \\
\left.F_{\text {organizational }}^{i} ; F_{\text {technological }}^{i} F_{\text {investment }}^{i}\right)
\end{array}\right) \rightarrow \max \right.
$$

Taking into account the specificity of high-rise construction, among these factors, it is advisable to consider as key factors: organizational, technological and investment factors. This choice is due to the fact that these groups of factors have the most significant impact on the cost, risks, timing of the works under the project, these factors are amenable to change and control within the project management processes. The degree of influence of these factors depends on the characteristics of a particular project $[5,7]$.

Thus, the objective function (1) may be reduced to the following form:

$$
E_{\text {project }}=f\left\{\begin{array}{c}
\text { Organizational efficiency } \rightarrow \max \\
\text { Technological efficiency } \rightarrow \max \\
\text { Investment efficiency } \rightarrow \max
\end{array}\right.
$$

Within the framework of this article, the author singled out key particular functions for each group of factors under consideration:

$$
\begin{gathered}
\text { Organizational efficiency }=f\left\{\begin{array}{l}
\text { logistics costs } \rightarrow \text { min } \\
\text { combination of consumer flows } \rightarrow \text { max }
\end{array}\right. \\
\text { Technological efficiency }=f\left\{\begin{array}{l}
\text { total cost of use of equipment } \rightarrow \text { min } \\
\text { technological sustainability } \rightarrow \text { max }
\end{array}\right. \\
\text { Investment efficiency }=f\left\{\begin{array}{c}
\text { commercial profitability } \rightarrow \text { max } \\
\text { cost of capital raised } \rightarrow \text { min }
\end{array}\right. \\
\text { ratio of profitability and risks } \rightarrow \text { max }
\end{gathered}
$$

\section{Results}

Based on the identified groups of factors and key particular functions, author developed a system of principles for the formation of an effective concept for multifunctional high-rise construction investment projects and a corresponding principal model (Figure 1). 


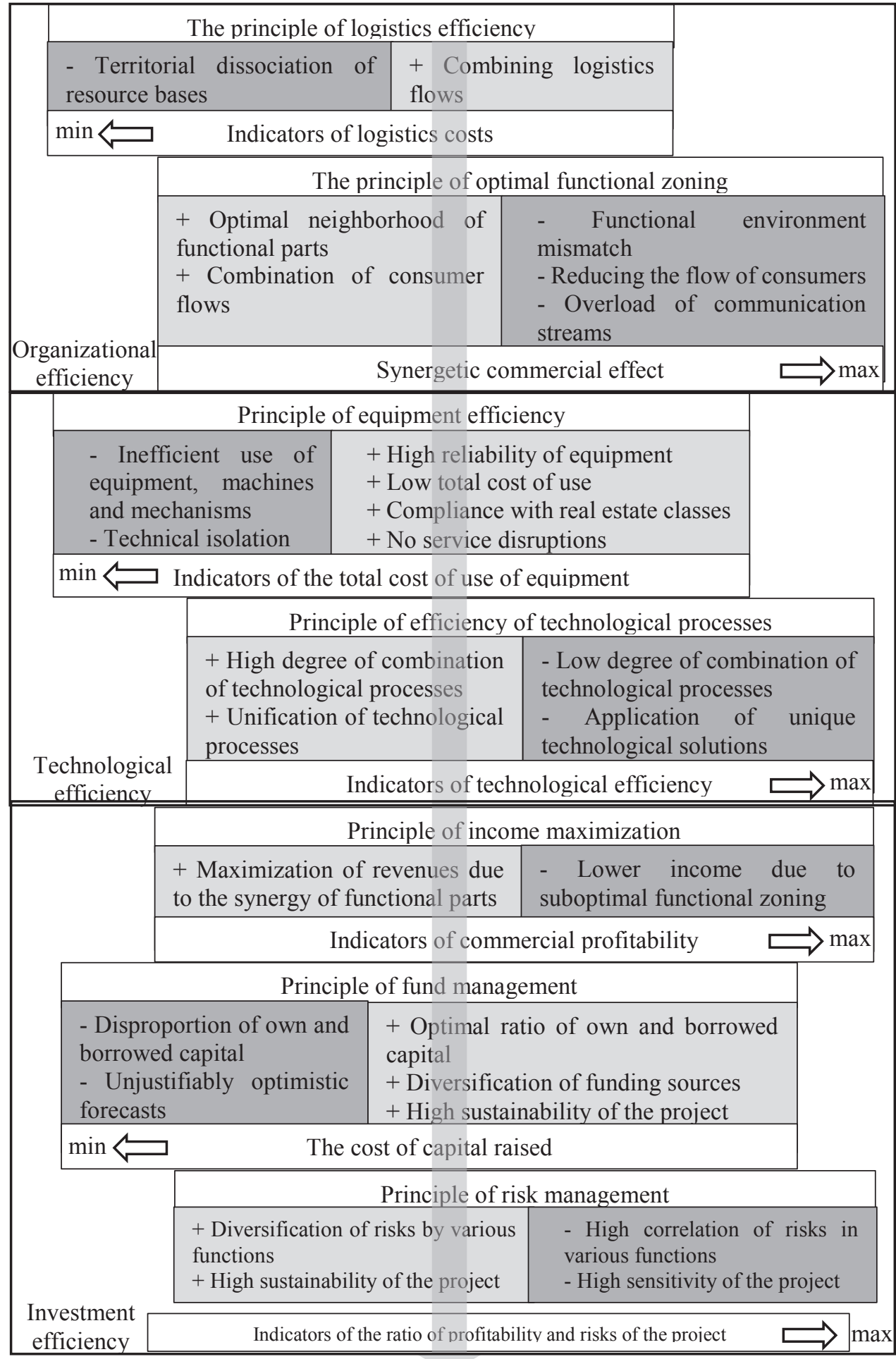

Target area for the effectiveness of the concept

Fig. 1. Model of the formation of an effective concept of investment projects of high-rise construction. 
In this model, the target area for the effectiveness of the concept of the multifunctional high-rise construction investment project is represented as an axis, and the blocks intersecting the axis contain the principles of efficiency for each of the key groups of factors and the target striving for maximum or minimum. It should be noted that the factors under consideration are not fully independent of each other and, accordingly, the control impacts on individual factors and groups of factors cause the emergence of synergistic effects in the context of the impact on the overall effectiveness of the project. Thus, the proposed principles for the formation of an effective concept of investment projects should be considered comprehensively within the framework of a unified management system.

\section{Discussion}

\section{The principle of logistics efficiency.}

When forming the concept of the project, it is expedient to plan the flows of resource support for all technological processes (both during construction and operation of the facility), which, when combined, reduce logistics costs [8]. Within the framework of logistic networks, it is allowed to increase costs for individual flows, provided that this will lead to an increase in the efficiency of the project as a whole.

\section{The principle of optimal functional zoning.}

When forming the concept of spatial zoning of a multifunctional high-rise object, it is necessary to consider the influence on the efficiency of the object's operation of such factors as the optimal neighborhood of functional elements, the combination of consumer flows, preferences for location within a high-rise building [9].

\section{Principle of equipment efficiency.}

Since the cost of equipment is a significant part of the total cost of the high-rise construction project, it is advisable to plan types and types of equipment at the stage of concept formation and further design, which are characterized by an optimal ratio of reliability and the volume of total costs throughout the life of the operation [10-12].

It is necessary to conduct an analysis of the conformity of the proposed equipment with the criteria for determining the classes of commercial real estate in accordance with certain types of functional purpose. It is also advisable to consider the possible risks associated with the interaction of entities in the event of the purchase and further maintenance of equipment produced in other countries.

\section{Principle of efficiency of technological processes.}

In order to reduce the duration and cost of building high-rise buildings in the formation of the concept and design, it is expedient to strive to reduce the number of unique solutions, to unify and combine the technological processes of construction [13].

It is also advisable to consider technological solutions that are most appropriate for the organization of construction on a particular land plot. Within the framework of operation of a multifunctional facility, unification and combination of technological processes related to the functioning of hotel functional units allows achieving synergy effect and, as a result, reducing operational costs and improving project efficiency [9].

\section{Principle of income maximization.}

The choice of functional parts within the multifunctional high-altitude facility and the determination of their ratio should be aimed at providing the maximum synergetic effect increasing the performance indicators for the functioning of each individual parts and the object as a whole. In some cases, it is also possible to create separate elements within a multifunctional facility that are not effective in themselves, but increase the efficiency of other elements by increasing the prestige, comfort or inflow of potential consumers $[9,14]$.

Principle of fund management. 
Since insufficient funding is one of the main reasons for the excess of the planned construction dates and the overall efficiency of high-rise construction projects, it is necessary to take into account pessimistic forecasts of the project financial plans and to choose financing strategies in favor of more conservative ones that ensure optimal the ratio of equity and borrowed funds of investors, strategies [15].

\section{Principle of risk management.}

For investment projects of commercial real estate of various functional types, various risks that arise under the influence of factors of different economic nature are often characteristic. In this regard, when selecting the functional parts within the multifunctional high-rise facility and determining their ratios, it is expedient to conduct a correlation analysis of risks and on its basis a version of the concept that is characterized by an acceptable level of integrated risk of the project.

\section{Conclusions}

The development of high-rise construction in Russia currently has a high dynamics, but there are a number of development directions that are characterized by substantial reserves of improving the efficiency of investment projects, including optimization of town-planning and functional-typological concepts of construction, improving procedures for selecting and justifying technical, technological and organizational design decisions, etc.

The model of formation of an effective concept of investment projects of multifunctional high-rise construction developed by the author can contribute to the development of methodological tools in the field of managing the implementation of high-rise construction projects, taking into account their specificity in the current economic conditions.

\section{References}

1. G. Ptichnikova, Procedia Engineering, 165, 1903-1910 (2016)

2. V. Zhilov, High-rise construction in Russia: present and prospects, Stroyprofile, 2, 34 (2007)

3. I. Afanasenko, V. Borisova, Economic logistics (Peter, Saint Petersburg, 2013)

4. A. Volkov, V. Chulkov, R. Kazaryan, Procedia Engineering, 91, 373-376 (2014)

5. P. Feng, W. Xingkuan, Procedia Engineering, 21, 943-947 (2011)

6. T. Ahmad, A. Aibinu, M. Thaheem, Procedia Engineering, 180, 1695-1704 (2017)

7. J. Tamošaitienè, E. Gaudutis, M. Kračka, Procedia Engineering, 57, 1151-1155 (2013)

8. A. Murzin, Real estate: economics, evaluation and development (Phoenix, Rostov on Don, 2013)

9. E. Kalcheva, A. Taki, Y. Hadi, Procedia - Social and Behavioral Sciences, 216, 960-973 (2016)

10. G. Savitskaya, Analysis of economic activity of enterprises (New knowledge, Minsk, 2004)

11. N. Gohl, A. Loose, S. Stark, H. Drück, Energy Procedia, 48, 1365-1373 (2014)

12. I. Puķīte, I. Geipele, Procedia Engineering, 172, 905-912 (2017)

13. G. Sternik, S. Sternik, N. Tulinova, Real Estate Development (Moscow, Prospekt, 2016)

14. D. Ben-Shahar, Y. Deng, E. Sulganik, Journal of Housing Economics, 18-1, 25-33 (2009)

15. A. Yudina, Technological processes in construction (Academy, Moscow, 2013) 